Median DLCO values for pre- and post RTX were 71.0\% (60.0-77.0) and 63.0\% (47.0-74.0), respectively $(p=0.061)$. Median pre and post-RTX FVC were $74.0 \%$ $(61.0-99.0)$ and $84.0 \%(63.0-100.0)$, respectively $(p=0.28)$. After a median of 2.7 years, $11(55.0 \%)$ patients had stable disease, $2(10.0 \%)$ patients had regression of RA-ILD and 7 (35.0\%) patients had progressive disease. Sex, age, seropositivity and radiographic patterns were not associated with progression. In total, 23 adverse events were detected in $11(42.3 \%)$ patients. Five of them were serious infections requiring hospitalization, mostly pneumonia. Other adverse events were simple infections and surgeries such as arthroplasty. RTX was stopped in $4(15.4 \%)$ patients due to infections secondary to hypogammaglobulinemia in 2 , malignancy in 1 and allergic reaction in 1.

Conclusion: RTX seems to achieve stabilization/improvement of RA-ILD with fewer adverse events. However, given that RA-ILD develops post-RTX, it is not a panacea; therefore, we need more effective treatment modalities in the case of RA-ILD.

Table 1. Characteristics of 26 patients with RA-ILD treated with rituximab

\begin{tabular}{ll}
\hline Age at first RTX infusion, median (IQR), years & $61.2(57.1-65.1)$ \\
RA disease duration at first RTX, median (IQR), years & $10.1(4.3-29.7)$ \\
ILD disease duration at first RTX, median (IQR), years & $1.9(0.1-4.5)$ \\
Age at RA diagnosis, median (IQR), years & $51.1(40.0-60.6)$ \\
Age at ILD diagnosis, median (IQR), years & $58.3(53.9-63.3)$ \\
Male patient, n (\%) & $16(61.5)$ \\
RF positivity, n (\%) & $25(96.2)$ \\
ACPA positivity, n (\%) & $20(90.9)$ \\
CRP levels, mg/L, mean (SD) & $40.3(58.9)$ \\
ESR levels, mean (SD) & $37.7(18.2)$ \\
Smoking status, n (\%) & $16(64.0)$ \\
Prior TNF inhibitor treatment, n (\%) & $5(19.2)$ \\
DAS28 at first RTX infusion, mean (SD) & $5.3(1.5)$ \\
Radiographic pattern, n (\%) & \\
UIP & $7(26.9)$ \\
NSIP & $8(30.8)$ \\
OP & $2(7.7)$ \\
Indeterminate & $8(30.8)$ \\
Others & $1(3.8)$ \\
Follow-up duration, median (IQR), years & $2.5(1.2-3.7)$
\end{tabular}

RA-ILD = Rheumatoid arthritis-related interstitial lung disease, $R T X=$ rituximab, $R A=$ rheumatoid arthritis, $\mathrm{RF}=$ rheumatoid factor, $\mathrm{ACPA}=$ anti-citrullinated protein antibody, $\mathrm{TNF}=$ tumor necrosis factor, $\mathrm{CRP}=\mathrm{C}$-reactive protein, $\mathrm{ESR}=$ erythrocyte sedimentation rate, $\mathrm{UIP}=$ usual interstitial pneumonia, NSIP = non-specific interstitial pneumonia, $\mathrm{OP}=$ organizing pneumonia

Disclosure of Interests: None declared

DOI: 10.1136/annrheumdis-2021-eular.731

\section{POS0598 COMPARISON OF INJECTION SITE REACTIONS AND INJECTION SITE ERYTHEMA BETWEEN YLB113 AND ETANERCEPT REFERENCE PRODUCT FROM PHASE 3 ACTIVE COMPARATOR STUDY (STUDY NO. YLB113-002)}

D. Stefanidis ${ }^{1}$, U. $G^{2}$, J. Sánchez-Bursón ${ }^{3}$, C. Shah ${ }^{4}$, D. Bakhle ${ }^{4} .{ }^{1}$ Viatris GmbH, Medical Affairs, Bad Homburg, Germany; ${ }^{2}$ Viatris, Biostatistics, Bangalore, India; ${ }^{3}$ Hospital Infanta Luisa, Rheumatology, Sevilla, Spain; ${ }^{4}$ Lupin LTD, Clinical, Pune, India

Background: YLB113 is an etanercept biosimilar approved in all indications of its etanercept Reference Product (RP). Therapeutic equivalence in terms of clinical efficacy, safety and immunogenicity was previously demonstrated in a pivotal multicenter, double-blind, randomized, parallel-group, active-control, comparative study (YLB113-002) in rheumatoid arthritis (RA) subjects. ${ }^{1,2}$ Similar incidence of treatment emergent adverse events (TEAEs) was seen in both treatment arms except for injection site reactions (ISRs) and injection site erythema (ISE), both of which were less frequent in subjects treated with YLB113.

Objectives: This post-hoc analysis was performed to further evaluate the differences in the incidence of ISRs and ISE during the 24 week treatment when the subjects with RA were treated with $50 \mathrm{mg}$ of YLB113 or RP given once a week as a SC injection along with methotrexate.

Methods: Safety analysis set (263 in YLB113 arm and 254 in RP arm) was considered for this analysis.

Local reactions at the site of injection were assessed at each of eight study visits. The number of subjects who experienced ISRs and ISE were statistically compared for YLB113 and RP. The risk difference and 95\% confidence interval $(\mathrm{Cl})$ were computed between arms to understand the magnitude of difference in the incidence of events. The statistical significance of between group difference was tested using chi-square test.

Results: The result of this analysis showed a statistically significant difference in the incidences of ISRs and ISE between subjects who received YLB113 and RP. The risk difference between YLB113 and RP arms for ISR was $-9.98 \%(95 \%$ CI, WALD $-14.81 \%,-5.15 \%)$ and, for ISE it was $-7.94 \%$ (95\% CI, WALD $-11.96 \%$,
- 3.92\%; Table 1). This could be possibly explained by the absence of latex in the syringe needle cap of YLB113.

Table 1. Differences in ISRs and ISEs between YLB113 and Reference Product (RP)

\begin{tabular}{|c|c|c|c|c|}
\hline \multirow[t]{3}{*}{ Event } & \multirow{2}{*}{$\begin{array}{l}\text { YLB113 } \\
\text { N=263 }\end{array}$} & \multirow{2}{*}{$\begin{array}{l}\mathrm{RP} \\
\mathrm{N}=254\end{array}$} & \multicolumn{2}{|l|}{ YLB113 vs RP } \\
\hline & & & & \\
\hline & $\begin{array}{l}\text { No of subjects } \\
\text { with events [n(\%) }\end{array}$ & $\begin{array}{l}\text { No of subjects } \\
\text { ]ith events } \\
[n(\%)])\end{array}$ & $\begin{array}{l}\text { Risk Diff (95\%Cl, } \\
\text { WALD) }\end{array}$ & $\begin{array}{l}\text { P-value } \\
\text { (Chi- } \\
\text { Square) }\end{array}$ \\
\hline $\begin{array}{l}\text { Injection-site } \\
\text { reactions }\end{array}$ & $10(3.8 \%)$ & $35(13.8 \%)$ & $\begin{array}{l}-9.98 \%(-14.81 \% \\
-5.15 \%)\end{array}$ & $<0.0001$ \\
\hline $\begin{array}{l}\text { Injection-site } \\
\text { erythema }\end{array}$ & $5(1.9 \%)$ & 25 (9.8\%) & $\begin{array}{l}-7.94 \%(-11.96 \% \\
-3.92 \%)\end{array}$ & 0.0001 \\
\hline
\end{tabular}

Conclusion: YLB113 has shown statistically significant lower incidences of ISRs (P-value $<0.0001$ ) and ISEs ( $\mathrm{P}$ value 0.0001$)$ compared to RP. This property may translate to a better acceptability by patients.

\section{REFERENCES:}

[1] EULAR Abstract AB0416 (2019). Ann Rheum Dis, volume 78, supplement 2 , year 2019, page A1670

[2] Yamanaka H, Kamatani N, Tanaka Y, et al. A Comparative Study to Assess the Efficacy, Safety, and Immunogenicity of YLB113 and the Etanercept Reference Product for the Treatment of Patients with Rheumatoid Arthritis. Rheumatol Ther. 2020;7(1):149-163.

[3] Viatris Etanercept Summary of Product Characteritics May 2020

Disclosure of Interests: Dimitris Stefanidis Employee of: Viatris GmbH Sr. Director, Global Medical Affairs Lead, Immunology Biosimilars, Unmesh G Employee of: Viatris, Juan Sánchez-Bursón: None declared, Chirag Shah Shareholder of: As an employee, Shareholder of Lupin LTD, Employee of: Employee of Lupin LTD, Dhananjay Bakhle Shareholder of: As part of Employee Stock Options Plan from Lupin LTD, Employee of: Employee of Lupin LTD

DOI: 10.1136/annrheumdis-2021-eular.829

\section{POS0599 DISEASE ACTIVITY IN PATIENTS WITH RA BY SEROSTATUS AND TREATMENT LINE, FOLLOWING TREATMENT WITH ABATACEPT: RESULTS FROM AN INTERNATIONAL OBSERVATIONAL STUDY}

R. Alten ${ }^{1}$, X. Mariette ${ }^{2}$, R. M. Flipo ${ }^{3}$, R. Caporali ${ }^{4,5}$, M. H. Buch ${ }^{6,7}$, Y. Patel ${ }^{8}$, R. Sanmarti ${ }^{9}$, S. Marsal ${ }^{10}$, M. T. Nurmohamed ${ }^{11}$, H. Griffiths ${ }^{12}$, P. Peichl ${ }^{13}$, B. Bannert ${ }^{14}$, A. Forster ${ }^{15}$, M. Chartier ${ }^{16}$, Y. Elbez $^{17}$, C. Rauch ${ }^{18}$, K. Lozenski ${ }^{19}$, V. Khaychuk ${ }^{20} .{ }^{1}$ Schlosspark-Klinik University, Department of Internal Medicine, Rheumatology, Berlin, Germany; ${ }^{2}$ Université Paris-Saclay, AP-HP, Hospital Bicêtre, Department of Rheumatology, Paris, France; ${ }^{3}$ Centre Hospitalier Universitaire de France, Department of Rheumatology, Lille, France; ${ }^{4}$ University of Milan, Department of Clinical Sciences and Community Health, Milan, Italy; ${ }^{5}$ G. Pini Hospital, Clinical Rheumatology Unit, Milan, Italy;

${ }^{6}$ University of Leeds, Leeds Institute for Rheumatic and Musculoskeletal Medicine, Leeds, United Kingdom; ${ }^{7}$ University of Manchester, Division of Musculoskeletal \& Dermatological Sciences, Manchester, United Kingdom; ${ }^{8}$ Hull Royal Infirmary, Department of Rheumatology, Hull, United Kingdom ${ }^{9}$ Hospital Clínic de Barcelona, Rheumatology Department, Barcelona, Spain; ${ }^{10}$ Hospital Universitari Vall d'Hebron, Rheumatology, Barcelona, Spain; ${ }^{11} A R C$ Amsterdam University Hospitals - VU University Medical \& Reade, Department of Rheumatology, Amsterdam, Netherlands; ${ }^{12}$ University Hospital Geelong, Barwon Rheumatology Service, Geelong, Australia; ${ }^{13}$ Evangelical Hospital, Department of Internal Medicine, Vienna, Austria; ${ }^{14}$ Universitätsspital Basel, Rheumatologische Universitätsklinik, Basel, Switzerland; ${ }^{15}$ Schulthess Klinik, Department of Rheumatology, Zürich, Switzerland; ${ }^{16}$ Bristol Myers Squibb, Non-Registrational Data Generation, Rueil-Malmaison, France; ${ }^{17}$ Deepscover, Biostatistics, Puteaux, France ${ }^{18}$ Bristol Myers Squibb, Medical Immunology \& Fibrosis, Munich, Germany; ${ }^{19}$ Bristol Myers Squibb, Immunology and Fibrosis, Princeton, United States of America; ${ }^{20}$ Bristol Myers Squibb, US Medical Immunology and Fibrosis, Princeton, United States of America

Background: RF and anti-citrullinated protein antibodies (ACPAs) are associated with a severe and aggressive disease course in patients with RA. ${ }^{1}$ Abatacept is a selective co-stimulation modulator for the treatment of RA. ${ }^{2}$ ASCORE (Abatacept SubCutaneOus in Routine Clinical PracticE; NCT02090556) was a 2-year, observational, prospective, multicentre study of SC abatacept for the treatment of RA in routine clinical practice. ${ }^{3}$

Objectives: To determine if serostatus and treatment line impacted disease activity in patients enrolled in the ASCORE study. 